Structure of Metallic Catalysts. By J. R. Anderson. Pp. ix +469 . (Academic: New York and London, June 1975.) £12.60; $\$ 33.75$.

THE technical importance of catalysts is such that an understanding of their structure is of obvious importance, whether from the view-point of the extent of surface accessible to reactants, or of the more intimate details of surface topography, chemistry, or electronic structure which might influence adsorption processes. Also, in the case of supported catalysts, the structure of the substrate can determine the state of dispersion of the metal and perhaps contribute to the overall reaction. This book is the first attempt to bring together information in these areas from the plethora of published literature, and from this aspect alone is a considerable achievement.

Available information on the structure of typical metallic phase catalysts is covered in some detail, particularly that relating to model systems where

\section{Metallic catalysts}

surface contamination can be more carefully controlled and which can therefore be used as standards for comparison. There are chapters on supports, massive, and dispersed, metal catalysts, and the structure and properties of small metallic particles. The book concludes with an outline of some appropriate techniques for the physical and chemical investigation of such structures, and there is an appendix which describes the preparation of some examples of typical metallic catalysts.

The state and scope of the subject dictate that the work be largely descriptive and of a review nature. It is, however, well and critically written, acceptably illustrated, and generally readable. It should make an admirable starting point for those entering the fields of catalysis or surface chemistry; the wealth of detail, some of it in useful tabular form, and the large number of quoted references, unfortunately without an author index, will also make it a useful addition to the libraries of any academic or industrial laboratory engaged in similar studies.

G. K. L. Cranstoun

\section{Opiate receptors}

Opiate Receptor Mechanisms: Neurochemical and Neurophysical Processes in Opiate Drug Action and Addiction. (Based on a work session of the Neurosciences Research Program.) By Solomon H. Snyder and Steven Matthysse. Pp. 116+vi. (MIT Press: Cambridge, Massachusetts and London, June 1975.) \$8.95.

THIS book is a record of a Work Session of the Neurosciences Research Program sponsored by the Massachusetts Institute of Technology and held in Boston during May 1974. The symposium was an unqualified success because it came at a time when the work of several groups, particularly those of A. Goldstein, L. Terenius, S. H. Snyder and C. B. Pert, and E. J. Simon, had greatly contributed to our knowledge of the nature and distribution of opiate receptors.

When the symposium was planned, various lines of indirect evidence had accumulated which suggested that there were in the central nervous system endogenous ligands that interacted with the opiate receptors. Evidence for the existence of such ligands was presented by L. Terenius, and by $\mathbf{J}$. Hughes and $\mathrm{H}$. W. Kosterlitz. G. W. Pasternak and S. H. Snyder mentioned supporting evidence which was updated in the published version.
These two sections are probably the most topical parts of the book. In the introduction, there is a brief review of the chemistry and action of opiates for readers unfamiliar with the field. The second chapter of the book deals with the biochemical identification of opiate receptors and the third with agonistantagonist interactions. The fourth considers neural mechanisms and contains a discussion by D. J. Mayer of the interesting experiments on analgesia induced by electrical stimulation of the periaqueductal grey matter and its prevention by the opiate antagonist, naloxone. The fifth chapter deals with biochemical phenomena in opiate action and addiction, the sixth with addiction, the seventh with the discussion review on further research. The final chapter is a stimulating and provocative essay by $\mathbf{S}$. H. Snyder on a model of opiate receptor function with implications for a theory of addiction.

This is a well-produced book presenting expertly and critically the state of our knowledge in an important field. Because the various chapters are not written by the individual authors but by the editors with the help of a small number of participants, the style is uniform and pleasing. It is unavoidable that part of the book has already been overtaken by events in a field in which a considerable number of workers are in constant and vigorous competition with each other

H. W. Kosterlitz

\section{Hydro, azo,} azoxy

The Chemistry of the Hydrazo, Azo and Azoxy Groups. Edited by Saul Patai. Part 1: Pp. xiv +1-598. Part 2: Pp. $\quad$ xiv + 599-1,190. (Wiley/Interscience: London and New York, September 1975.) $£ 17$ each part; $£ 33$ two volume set.

THIS is the sixteenth volume to appear in Professor Saul Patai's monumental series on the chemistry of individual functional groups; there are five volumes to come. There is no detailed consideration of azo dyes on grounds of space, and diazonium salts and diazoalkanes are to be covered in a subsequent volume.

The general style, arrangement and coverage closely parallel those of previous volumes, including the usual articles on structure, thermochemistry, electrochemistry, photochemistry, radiation chemistry, mass spectra, basicity and complexing, of the three groups. There are also interesting accounts of chiroptical properties, directing and activating effects, biological formation and reactions, syntheses and uses of isotopically labelled species, rearrangements (a particularly good and interesting contribution), ionic reactions, and radical reactions. There is a useful chapter on preparative procedures, and also two interesting longer chapters on oxidation and synthetic uses, and reduction and synthetic uses, of the groups. Finally there are more specific, and specialised items on transition metal chemistry of the groups, on conformational analysis of hydrazines, and a long but very interesting chapter on the formation and fragmentation of cyclic azo compounds.

The literature seems in general to have been surveyed to the end of 1973 - I could find only fourteen references, out of many hundreds, dated 1974although this datum line does not seem to be uniform for all articles. The subiect index could usefully have been a little more comprehensive, perhaps at the expense of the author index that one would have thought to be relatively less important. The general printing and layout of the reaction schemes is markedlv superior to that in most of the previous volumes.

Peter Svkes

Erratum. Gordon and Breach, nublishers of Composition of Cosmic Radiation by Annarao, reviewed jointly with another book on the same subject (Nature, 258, November 6 , page 40 ), point out that the reviewer's statement about the comnarative prices per page of the two hooks is incorrect. The book by Apparao has, in fact, the lower price per page We apologise for the error. 